\title{
ANALYSIS OF CESAREAN SECTION AT A TERTIARY CARE CENTRE IN EASTERN NEPAL ACCORDING TO ROBSON'S TEN GROUP CLASSIFICATION SYSTEM (TGCS): A HOSPITAL BASED CROSS SECTIONAL STUDY
}

Das $A^{1^{*}}$, Agrawal $A^{2}$, Bhandari $S^{1}$, Rajbhandari $S^{1}$, Rimal $S P^{1}$

\section{Affiliation}

1. Assistant Professor, Obstetrics and Gynaecology, BP Koirala Institute of Health Sciences, Dharan.

2. Additional Professor, Obstetrics and Gynaecology, BP Koirala Institute of Health Sciences, Dharan

\section{ARTICLE INFO}

Received : 23 July, 2020

Accepted : 21 November, 2020

Published : 22 December, 2020

(C) Authors retain copyright and grant the journal right of first publication with the work simultaneously licensed under Creative Commons Attribution License CC - BY 4.0 that allows others to share the work with an acknowledgment of the work's authorship and initial publication in this journal.

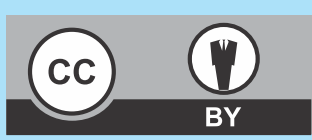

ORA 201

DOI: https://doi.org/10.3126/bjhs.v5i3.33688

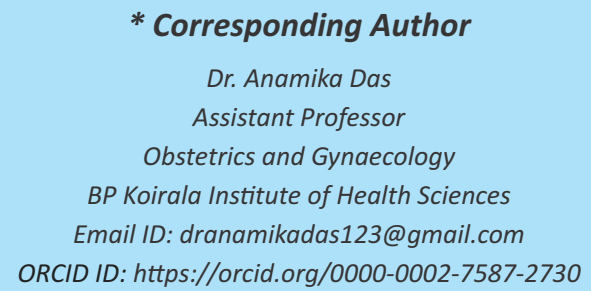

\section{Citation}

Das A, Agrawal A, Bhandari S, Rajbhandari S, Rimal SP. Analysis of Cesarean Section at A Tertiary Care Centre in Eastern Nepal According to Robson's Ten Group Classification System (TGCS): A Hospital Based Cross Sectional Study. BJHS 2020;5(3)13. 1171 - 1175.

\section{ABSTRACT}

\section{Introduction}

Cesarean section is on the rising trend, so WHO proposes that health care facilities uses the Robson's 10 group classification system to audit their Cesarean section rates. This classification will help to develop strategies to reduce these rates.

\section{Objective}

The objective of this study was to classify the women coming for delivery into the 10 Robson's group, to interpret the 10 group classification and to know the highest rate of cesarean section in the group.

\section{Methodology}

This was a hospital based cross sectional study carried out in the Department of Obstetrics and Gynaecology, for a period of 6 months. All women undergoing delivery were recruited for study. Based on the patient's obstetric parameters, women were assigned to one of 10 groups as per Robson's 10 -group classification system. The relative size of each group, the cesarean section rate in each group, and the absolute and relative contributions to the overall cesarean section rate was then reported.

\section{Result}

During the study period, the overall Cesarean Section rate was $33.40 \%$. Highest contribution was by Robson's Group 2 (Nulliparous, single cephalic, $\geq 37$ weeks, induced or CS before labor $(9.84 \%)$ followed by Group 1 (Nulliparous, single cephalic, $\geq 37$ weeks, in spontaneous labor)(7.73\%) and Group 5 (Previous CS, single cephalic, $\geq 37$ weeks) (5.75\%). Least contribution was by Groups 8(All multiple pregnancies (including previous CS)and 9[All abnormal lies (including previous CS)] $0.20 \%$ and $0.27 \%$ respectively. All women in group 9 (all abnormal lies including previous CS)had $100 \%$ Cesarean rate.

\section{Conclusions}

With reductions in the primary cesarean section rates and encouraging patients for VBAC could reduce the contribution of Robson's groups towards the absolute Cesarean Section rates.

\section{KEYWORDS}

Cesarean section, contribution, Robson's classification, Ten Group classification system 


\section{INTRODUCTION}

Cesarean section (CS) rate is increasing worldwide in both developed and developing world over the past three decades. ${ }^{1-3}$ Developed countries like the Unites States have seen a drastic rise in CS from 1996 to-2011. ${ }^{4}$ The developing world too have seen a similar rise. The rate of CS delivery has been relatively low in Nepal with $5 \%$ in $2014 .^{5}$ Despite this, in the last decade, the CS rate in Nepal has quadrupled. ${ }^{6} \mathrm{CS}$ is more frequent among urban women (15\%) than among the rural women(3.5\%). Tertiary care centers have high CS rates but areas where health care facilities are are not available may have maternal deaths due to lack of CS facilities. ${ }^{5-7}$ Hence forth, cesarean section rates in tertiary health care facilities should be assessed which would represent the CS rates of the population catered by that center.

According to The World Health Organization (WHO),1985: "for any region to have a cesarean section (CS) rate higher than $10-15 \% "$ is not justified. ${ }^{8}$ The rising cesarean section rates poses no substantial maternal and perinatal benefits, however higher rates could lead to negative consequences in maternal and child health. ${ }^{9-10}$ Lack of standardized and internationally-acceptable classification system to monitor the patients and compare section rates in a consistent manner, has been one of the factors preventing a better understanding of this trend and underlying causes . ${ }^{11}$

In 2011, after a systematic review and critical appraisal of the available classifications done for cesarean section, it has been concluded that women-based classifications in general and Robson's 10-group classification in particular, would be in the best option to fulfill current international and local needs. ${ }^{12}$ Henceforth various reviews have recommended that an internationally applicable classification should be most appropriately placed in building upon this classification.

Robson Ten Group classification is a system that classifies women into 10 groups based on their obstetric characteristics (parity, previous CS, period of gestation, onset of labour, fetal presentation and number of fetuses) without needing the indication for CS. ${ }^{11}$

\section{Definition of each group.}

1. Nulliparous, single cephalic, $>=37 \mathrm{wks}$, in spontaneous labor.

2. Nulliparous, single cephalic, $>=37$ wks, induced or CS before labor.

3. Multiparous (excluding previous CS), single cephalic, $>=37$ weeks in spontaneous labor.

4. Multiparous (excluding previous CS), single cephalic, $>=37$ weeks, induced or CS before labor.

5. Previous CS, single cephalic, $>=37$ weeks.

6. All nulliparous breeches.

7. All multiparous breeches (including previous CS).

8. All multiple pregnancies (including previous CS).

9. All abnormal lies (including previous CS).

10. All single cephalic, $=<36$ wks (including previous CS) Since 2001, when the Robson classification (also called the 10-group classification) was proposed, many facilities and countries have incorporated it in their routine clinical practice as a tool to monitor CS rates in their population and to evaluate the impact of changes in management that may alter theserates. ${ }^{13-16}$

\section{METHODOLOGY}

This was a hospital based descriptive, cross sectional study carried out in the Department of Obstetrics and Gynaecology, at a tertiary care centre in Eastern Nepal from August, 2018 to Jan, 2019. All women whether booked or unbooked, undergoing delivery whether vaginal delivery (spontaneous or induced) or cesarean section were recruited for the study at labour ward and postnatal ward. Parity, mode of previous delivery, gestational age, and onset of labour (spontaneous or induced), fetal presentation and number of fetuses without needing the indication of induction were the baseline variables. Data was collected from the case sheet, delivery notes of labour ward, post natal ward and operative notes in operation theatres and entered into proforma. These obstetric parameters helped to classify these patients to the 10 Group Robson's classification for the year 20182019. The cesarean section rates in the different groups and the contribution of each group to the overall rate of cesarean section was determined. According to Ray $A$ et al, the prevalence of the overall C-Section rate was $28 \% .{ }^{17}$ Considering $28 \%$ as the prevalence of overall Cesarean section rate, $95 \%$ Confidence interval, $80 \%$ power, $5 \%$ permissible error and $10 \%$ non-responders; the final sample size calculated using the following formula $\left(n=Z^{2} p q / d^{2}\right)$ was 990(minimum sample size). Ethical clearance was obtained from the Hospital Institutional Review Board prior to start the study. Data analysis was done using SPSS version 23.0; SPSS, Chicago, IL, USA. Percentages were calculated for the overall rate. The relative size of each Robson group, the caesarean section rate in each Robson group, and the absolute and relative contributions made by each to the overall caesarean section rate was reported.

\section{RESULTS}

During the study period, the total number of women who delivered were 4398. The total numbers of Cesarean Sections were 1469 and the overall CS rate for this period of time at our hospital was $33.40 \%$.These women were categorized according to Robson's classification Groups and analyzed as per the (table 1).

Robson's Group 2 (nulliparous, single cephalic, induced or CS before labour) had the greatest representation $9.84 \%$ in our population. This group was followed by nulliparous, single cephalic women at term in spontaneous labor (Robson's Group 1) (7.73\%) and women with a single cephalic presentation at term and previous CS (Group 5) (5.75\%). Maximum inductions were done in view of medical disorders of pregnancy like Gestational Diabetes Mellitus, Preeclampsia, Intrahepatic cholestasis of pregnancy followed by prelabour rupture of membranes and preterm prelabour rupture of membranes (PROM, PPROM). In patients undergoing inductions, mostly indications of cesarean were failed induction of labour and fetal distress. In Group 5, out of 263 in this group, 253 underwent Cesarean section. 190 women were fit for and were offered VBAC, 10 
accepted and rest chose elective section without going into labor.

Group 4 (Multiparous (excluding previous CS), single cephalic, >=37 weeks, induced or CS before labor)had a cesarean section rate of $62.5 \%$ suggesting high prelabour caesarean section/elective CS in multiparous women whereas group 3(Multiparous (excluding previous CS), single cephalic, $>=37$ weeks in spontaneous labor)had cesarean section rate of $10.93 \%$. Groups 8 (All multiple pregnancies (including previous CS) and 9 (All abnormal lies (including previous CS) had the least representation, $0.20 \%$ and $0.27 \%$ respectively (Table 1 ). Percentage wise group 9 had the greatest section rates of $100 \%$ meaning all women in this group underwent CS.This was followed by group 5 , (6 and 7 ) which had $96 \%$, and $80 \%$ respectively section rates. (Table 1)

Table 1: Description of Robson's Ten Group Classification (TGCS) System In Our Population

\begin{tabular}{|c|c|c|c|c|}
\hline \multirow[b]{2}{*}{ GROUPS COLUMN } & \multicolumn{4}{|c|}{ Overall CS Rate (\%) 1469/4398 (33.40\%) (6 mths) } \\
\hline & $\begin{array}{l}\text { Number of CS over } \\
\text { total number of } \\
\text { women in each } \\
\text { group COLUMN } 2\end{array}$ & $\begin{array}{l}\text { Relative size of } \\
\text { groups (\%) COLUMN } \\
\mathbf{3}\end{array}$ & $\begin{array}{c}\text { CS rate in each } \\
\text { group (\%) COLUMN } \\
4\end{array}$ & $\begin{array}{l}\text { Contribution made by } \\
\text { each group to ten } \\
\text { group overall CS rate } \\
\text { (\%) COLUMN } 5\end{array}$ \\
\hline $\begin{array}{l}\text { 1. Nulliparous, single cephalic, } \geq 37 \\
\text { weeks, in spontaneous labour }\end{array}$ & $340 / 1919$ & $1919 / 4398(43.63)$ & $340 / 1919(17.710)$ & $340 / 4398(7.73)$ \\
\hline $\begin{array}{l}\text { 2. Nulliparous, single cephalic, } \geq 37 \\
\text { weeks induced or CS before } \\
\text { labour }\end{array}$ & $433 / 600$ & $600 / 4398(13.64)$ & $433 / 600(72.16)$ & $433 / 4398(9.84)$ \\
\hline $\begin{array}{l}\text { 3. Multiparous (excluding p revious } \\
\text { CS) single cephalic, } \geq 37 \text { weeks, in } \\
\text { spontaneous labour }\end{array}$ & $117 / 1070$ & $1070 / 4398(24.32)$ & $117 / 1070(10.93)$ & $117 / 4398(2.66)$ \\
\hline $\begin{array}{l}\text { 4. Multiparous (excluding previous } \\
\mathrm{CS} \text { ) } \geq 37 \text { weeks induced or } \mathrm{CS} \\
\text { before labour }\end{array}$ & $145 / 232$ & $232 / 4398(5.27)$ & $145 / 232(62.5)$ & $145 / 4398(3.29)$ \\
\hline $\begin{array}{l}\text { 5. Previous CS, single cephalic } \geq 37 \\
\text { weeks }\end{array}$ & $253 / 263$ & $263 / 4398(5.97)$ & 253/263(96.19) & $253 / 4398(5.75)$ \\
\hline 6. All nulliparous breeches & $64 / 80$ & $80 / 4398(1.81)$ & $64 / 80(80.00)$ & $64 / 4398(1.45)$ \\
\hline $\begin{array}{l}\text { 7. All multiparous breeches } \\
\text { (including previous CS) }\end{array}$ & $29 / 36$ & $36 / 4398(0.81)$ & $29 / 36(80.55)$ & 29/4398(0.65) \\
\hline $\begin{array}{l}\text { 8. All multiple regnancies (including } \\
\text { previous CS) }\end{array}$ & $9 / 17$ & $17 / 4398(0.38)$ & $9 / 17(52.94)$ & $9 / 4398(0.20)$ \\
\hline $\begin{array}{l}\text { 9. All abnormal lies (including } \\
\text { previous CS) }\end{array}$ & $12 / 12$ & $12 / 4398(0.27)$ & $12 / 12(100)$ & $12 / 4398(0.27)$ \\
\hline $\begin{array}{l}\text { 10. All single cephalic, } \leq 36 \text { weeks } \\
\text { (including revious CS) }\end{array}$ & $67 / 169$ & $169 / 4398(0.36)$ & $67 / 169(39.64)$ & $67 / 4398(1.52)$ \\
\hline
\end{tabular}

$\mathrm{CS}=$ cesarean Section

\section{DISCUSSION}

The cesarean section rates across the globe have been increasing though rates have varied from centre to centre. Our overall CS rate is $33.40 \%$. According to WHO, it is stated that at a population level, reductions in maternal and newborn mortality rates does not occur with cesarean section rates higher than $10 \%$. Our higher rates of cesarean section reflect the hospital cesarean section rates and not the population section rate. Ours is the biggest referral centre in the Eastern Nepal which receives several referrals from centres which are not well equipped. When compared to other countries our rates were comparable to that of USA (31.1\%) and Australia (30\%), higher than that of Norway (13.9\%). ${ }^{10,18-21}$

All groups were analyzed clinically according to Current Progress in Obstetrics \& Gynaecology by John Studd, results of the study Ten group classification system according to $\mathrm{M}$. Robson's et.al and Best Practice Research Clinical Obstetrics and Gynaecology. 22,23

In column 3, Group 1 plus 2 accounts for $35-42 \%$ of total woman. In our study it is $56 \%$ of total women. The increase in size may be due to the referral system at the tertiary hospital. The ratio of Group 1 and Group 2 is more than 2:1, suggesting less induction. The most important thing is to individualize every labour and so long as monitoring is good and mother and fetus are well, don't set a time limit while patient is in a tertiary centre. Proper management of labour is necessary to reduce the CS rate in this group. Attaining an adequate uterine contraction, proper use of oxytocin drip, use of partograph and proper treatment of dystocia, fetal monitoring in the labour unit will help to reduce the cesarean section rate in this group.

In column 3, Group 3 and 4 combined, usually represents 30$40 \%$ of women. In our study also Group 3 and 4 combined, constitute $29.59 \%$. Ratio of Group 3 and 4 is greater than Group 1 and 2. (4:1 > 3:1). Group 4 [multiparous (excluding previous (S)] $>37$ weeks, induced or CS before labour) has a cesarean section rate of $62.5 \%$ suggesting high prelabour cesarean section in multiparous women. This may be due to 
increased referral of more number of multiparous women with no live babies to the hospital.

In column 3, Group 5 the size is $5.97 \%$. A rate less than $10 \%$ suggests low previous cesarean section rate. Trial of labour after cesarean section (TOLAC) is the only remedy to decrease group $5 \mathrm{~s}$ contribution to cesarean section rates. However, decreasing the primary caesarean section rates is the key to reduce overall cesarean section rates. Adequate antenatal counselling and preparedness for VBAC may be helpful to decrease section rates.

In column 3, Group 6 and 7combined should represent for 3$4 \%$ of women. In our study the relative size is $2.10 \%$, suggesting incidence of breech being more in primigravida. This also correlated with the column 3, Group 10 which is $1.52 \%$ and is less than $4-5 \%$ confirming the less premature delivery rate. Also breech delivery in multis should be promoted.

In column 3, Group 8should contain $1.5-2 \%$ of women. The relative size in our study is $0.53 \%$ and is less though it is a tertiary hospital.

In Group 9, the relative size in third column should be 0.2 $0.6 \%$ and the CS rate should be $100 \%$. In our study the relative size and CS rate corresponds to the same. This group mainly represented the malpresentations and this part could have been reduced by versions. Both primi and multiparous particularly those with un-scarred uterus could undergo versions and stabilizing inductions. There is the general reluctance to offer External cephalic version(ECV) despite clear protocols and instruction on the procedure. Also, the fear and reluctance to carry out ECV creates reluctance to carry out an assisted vaginal breech delivery. Both skills must be taught and reinforced.

In column 3, Group 10 should represent $4-5 \%$ of women. It is $3.85 \%$ in our study and cesarean section rate is $39.64 \%$ suggesting less of preterm labour cesarean section rate.

In column 4, Group 1, the cesarean section rate should be less than $10 \%$. In our study, it is $17.7 \%$ suggesting high cesarean section rate in Group 1.

In column 4, Group 3, the caesarean section rate should not represent more than $3 \%$. But in our study, the caesarean section rate is $10.93 \%$. Subdivision of this group is essential to improve the data collection.

In Group 5, the Cesarean section rate should represent 50 $60 \%$, but in our study it is $96.19 \%$, suggesting subdividing women in this group to two previous sections is important.

In our population, Group 2 had the greatest representation followed by Groups 1 and 5. There is clear evidence from this finding that unsuccessful inductions of labour is the biggest contribution to the high cesarean section rate for both groups 2 and 4 . Therefore a critical review of induction protocols would have to be considered and probably modified or adhered to as much as possible.

\section{CONCLUSION}

Though the overall CS rate in the study is comparable to international studies, the contribution of the various
Robson's Group to the absolute Cesarean Section rates needs to be looked into. From this study it was found out that groups 2,1 and 5 were the major contributors to the overall caesarean section rates. Reducing the rate of primary cesarean sections, conducting adequate antenatal counselling and encouraging for VBAC, changing the protocols for labour dystocia and non-reassuring fetal status, training and encouraging obstetricians to perform versions if not contraindicated could help to reduce the contribution of Robson's groups towards the absolute CS rates. More studies using this classification is needed which would further help obstetricians and hospitals to formulate strategies to reduce their section rates till they reach the proposed WHO recommendations.

\section{RECOMMENDATION}

Though the sample size was comparatively small, this result clearly identified that global prevention of cesarean section should mainly focus on reducing primary section rates, adequate counselling and encouraging for VBAC, changing the norms for dystocia and non-reassuring fetal status, training and encouraging obstetricians to perform versions when not contraindicated. This study produced a baseline data, which will help in planning and designing health education and policy making for the population.

\section{LIMITATION OF THE STUDY}

The main strengths of our study include it is a prospective study and as BPKIHS is a tertiary health care centre treating many patients referred from eastern Nepal so to some extent it reflects the problem of eastern region of Nepal. These results will also allow future standardised comparisons with other datasets in the country. This study had certain limitations. It was a single hospital based study with comparatively small sample, so considering the community based study or multi-centered study with larger sample size would better reflect the actual scenario of this problem, Also we are unable to assess changes in the obstetric care capacity (gain or loss in infrastructure, availability of essential interventions, staffing, or other factors) over time and how these could have affected cesarean section use. Suboptimal medical record keeping might have adversely affected data quality.

\section{ACKNOWLEDGEMENT}

I would like to thank our labor room and postnatal ward doctors and sisters who helped me to collect the data and feed it into excel sheets.

\section{CONFLICT OF INTEREST}

None declared

\section{FINANCIAL DISCLOSURE}

None. 


\section{REFERENCES}

1. Betram AP, Merialdi M, Lauer JA, Bing-Shun W, Thomas J, Van Look $P$, Wagner. Rates of caesarean section: analysis of global, regional and national estimates. PaediatrPerinatEpidemiol. Mar; 21(2):98113.[DOI]

2. Zizza A, Tinelli A, Malvasi A, Barbone E, Stark M, De Donno A, Guido $M$. Caesarean section in the world: a new ecological approach. J Prev Med Hyg. 2011 Dec; 52(4):161-73.[PUB MED]

3. Litorp H, Kidanto H, Nystrom L, Darj E, Esse'n B. Increasing caesarean section rates among low-risk groups: a panel study classifying deliveries according to Robson at a university hospital in Tanzania. BMC Pregnancy Childbirth. 2013 May; 13:107. [DOI]

4. Martin JA, Hamilton BE, Ventura SJ, Osterman MJ, Mathews TJ. Births: Final data for 2011. Natl Vital Stat Rep. 2013 Jun 28; 62(1):1-69,72. [PUB MED]

5. World Health Organization. World health statistics 2014. [FULL TEXT.]

6. Prakash KC, Neupane S. Cesarean deliveries among Nepalese mothers: changes over time 2001-2011 and determinants. Arch Gynecol Obstet. 2014; 289(2):421-427. doi: 10.1007/s00404-0132976-8.[DOI]

7. Ministry of Health and Population; New Era; ICF International. Nepal Demographic and HealthSurvey2011. [FULL TEXT].

8. WHO (1985) Appropriate technology for birth. Lancet 2: 436-437.[PUB MED]

9. Villar J, Carroli G, Zavaleta N, Donner A, Wojdyla D, Faundes A, Velazco A, Bataglia V, Langer A, Narváez A, Valladares E, Shah A, Campodónico L, Romero M, Reynoso S, de Pádua KS, Giordano D, Kublickas M, Acosta A,Maternal and neonatal individual risks and benefits associated with caesarean delivery: multicentre prospective study. BMJ. 2007 Nov 17; 335(7628):1025.[DOI]

10. Lumbiganon P, Laopaiboon M, Gulmezoglu AM, Souza JP, Taneepanichskul S, Ruyan P, Attygalle DE, Shrestha N, Mori R, Nguyen DH, HoangTB, Rathavy T, Chuyun K, Cheang K, Festin M, Udomprasertgu IV, Germar MJ, Yanqiu G, Roy M,Carroli G, Ba-ThikeK, Filatova E, Villar J. Method of delivery and pregnancy outcomes in Asia: the WHO global survey on maternal and perinatal health 2007-08. Lancet 2010 Feb 6; 375(9713):490-9. [DOI]

11. Robson MS (2001) Classification of caesarean sections. Fetal and Maternal Medicine Review 12: 23-39.[DOI]

12. Torloni MR, Betran AP, Souza JP, Widmer M, Allen T, Gulmezoglu M, Meriadi M Classifications for cesarean section: a systematic review. PLoS ONE. 2011 Jan 20;6(1):e14566. [DOI]
13. CabezaVengoechea PJ, CalvoPe'rez A, Betra'n AP, Mas Morey MM, Febles Borges MM, et al. (2010) Clasificacio'n de cesa'reasporGrupos de Robson en dos periodoscomparativos en el Hospital de Manacor. Progresos en Obstetricia y Ginecología 53: 385-390.[DOI]

14. Kazmi T, Saiseema S, Khan S .Analysis of Cesarean Section Rate According to Robson's 10-group Classification. Oman Med J (2012) ;27: 415-417. [DOI]

15. Betran AP, Gulmezoglu AM, Robson M, Merialdi $M$, Souza JP,WoidylaD,WidmerM,CarroliG,TorloniMR,LangerA,VelascoA,Faund esA,AcostaA,ValladaresE,RomeroM,ZavaletaN,ReynosoS,Bataglia V WHO global survey on maternal and perinatal health in Latin America: classifying caesarean sections. Reprod Health. 2009 Oct 29; 6:18. [DOI]

16. Kelly S, Sprague A, Fell DB, Murphy P, AelicksN. Examining Caesarean Section Rates in Canada Using the Robson Classification System.JObstetGynaecol Can. 2013 Mar; 35(3):206-214.[DOI]

17. RayA, JoseS. Analysis of Caesarean-Section rates according to Robson's ten group classification system and evaluating the indications within the groups Int J ReprodContraceptObstet Gynecol. 2017 Feb; 6(2):[DOI]

18. Mac Dorman MF, MenackerF, Declercq E. Cesarean birth in the United States:epidemiology, trends, and outcomes. Clin Perinatol. 2008 Jun; 35(2):293-307. [DOI]

19. Stavrou EP, Ford JB, Shand AW, Morris JM, RobertsCL. Epidemiology and trends for Caesarean section births in New South Wales, Australia: a population-based study. BMC Pregnancy Childbirth. 2011 Jan; 11:8.[DOI]

20. Laws PJ, Sullivan EA. Australia's mothers and babies. Sydney 2007; 2009. [FULL TEXT]

21. Kolas $T$, Hofoss D, Daltveit AK, Nilsen ST, Henriksen $T$, Hager R, Ingermarssonl, Oian P. Indications for cesarean deliveries in Norway.Am J Obstet Gynecol. 2003 Apr; 188(4):864-70. [FULLTEXT]

22. Grace Neville, Micheal Robson, Caesarean Section Rates: Much Ado about Nothing or a Marker of Quality Care?, in John Studd, Seang Lin Tan. Frank A.Chevenak, Current progress in Obstetrics\&Gynaecology Vol-2 (Mumbai: Tree Life Media - Kothari Medical Subscription Services Pvt. Ltd.2014) 151-162.[FULL TEXT]

23. RobsonM,HartiganL, Murphy M. Method of achieving and maintaing an appropriate caesarean section rate. Best Practices \&Research Clinical Obstetrics and Gynaecology. 2013 Apr; 27(2):297-308. [DOI] 